\title{
10 p deletion in a Sri Lankan infant with partial DiGeorge syndrome
}

\author{
Manouri P Senanayake ${ }^{1}$, T C I Fernando ${ }^{2}$, R A D P M Jayawardhana ${ }^{2}$
}

Sri Lanka Journal of Child Health, 2014; 43(3): 171-173

(Key words: 10p deletion; partial DiGeorge syndrome; Sri Lankan infant)

\section{Introduction}

DiGeorge syndrome (DGS) is a diagnosis usually made early in life with the classical triad of congenital heart defect (conotruncal abnormalities in the majority) hypocalcaemia and thymic aplasia / hypoplasia ${ }^{1}$. Defective morphogenesis of the third and fourth branchial arches from where the thymus, parathyroid glands and the outflow tract of the heart originate explains this clinical syndrome ${ }^{2}$. Heterozygous chromosomal deletion at $22 \mathrm{q} 11.2$ is the well-known underlying cause for this relatively common and easily recognized chromosomal disorder $^{1,2}$. Feeding difficulties, palatal abnormalities, including cleft palate and the velo-cardio-facial syndrome, are other entities included in the chromosome 22q11.2 deletion syndrome.

We report an infant whose phenotype resembled chromosome 22q11 deletion syndrome but whose genotype showed $10 \mathrm{p}$ deletion syndrome with no abnormality of chromosome 22. This clinical presentation is explained by the deletion of the DiGeorge critical region 2 (DGCR2) identified on the short arm of chromosome 10. This rare syndrome highlights the need for genetic studies for accurate phenotype-genotype correlation in patients with DGS.

\section{Case report}

A girl with failure to thrive, difficulty in swallowing, congenital heart defects and recurrent respiratory tract infections developed hypocalcaemia and seizures at sixteen weeks of age. She was the first child of healthy, unrelated parents (mother 22 years, father 26 years) and was growth retarded at birth, weighing $1.86 \mathrm{~kg}$ at 38 weeks gestation. At age four

\footnotetext{
${ }^{1}$ Senior Professor in Paediatrics, Department of Paediatrics, Faculty of Medicine, Colombo, ${ }^{2}$ Registrar in Paediatrics, Professorial Paediatric Unit, Lady Ridgeway Hospital for Children Colombo
}

(Received on 24 June 2013: Accepted after revision on 30 August 2013) months physical examination found her poorly grown $(2.7 \mathrm{~kg})$. Weight, length and head circumference were all at $-3 \mathrm{SD}$. There was dysmorphism, which included hypertelorism, small hooded eyes, epicanthic folds, flat nasal bridge, prominent nostrils, receding chin, low set malformed ears, thin upper lip and bifid uvula (Figure 1).

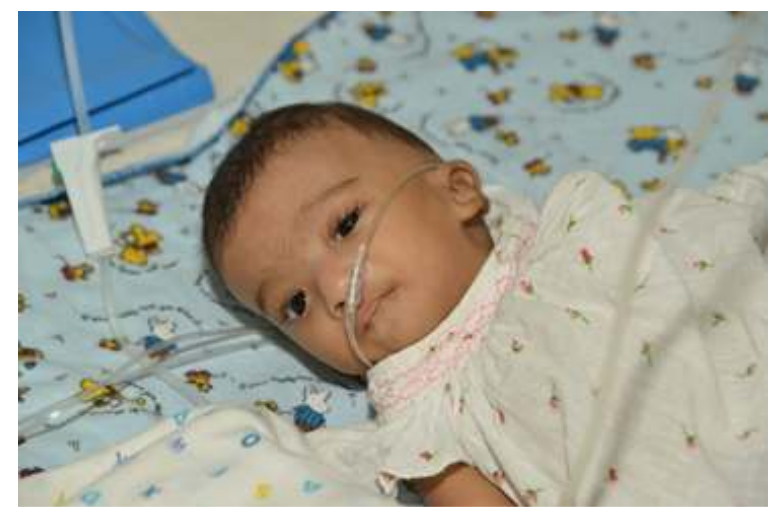

Figure 1: Characteristic facies resembling DiGeorge syndrome

There was a systolic murmur but no features of heart failure. Motor development was delayed with head lag. Bilateral sensori-neuronal hearing loss was present but she was alert and able to follow objects visually.

Laboratory investigations showed hypocalcaemia, normal serum sodium, potassium and magnesium. $\mathrm{T}$ cell activity was present. A narrow superior mediastinum was seen on chest radiography. Ultrasonography identified a small hypoplastic thymus in the anterior mediastinum. Echocardiography revealed a perimembranous ventricular septal defect, atrial septal defect and small patent ductus arteriosus. Kidney and brain ultrasound were normal.

Chromosome culture and karyotyping showed a karyotype of 46,XX,del(10)(p12.3 $\rightarrow 15)$.(Figure 2) Parental karyotypes were normal. 


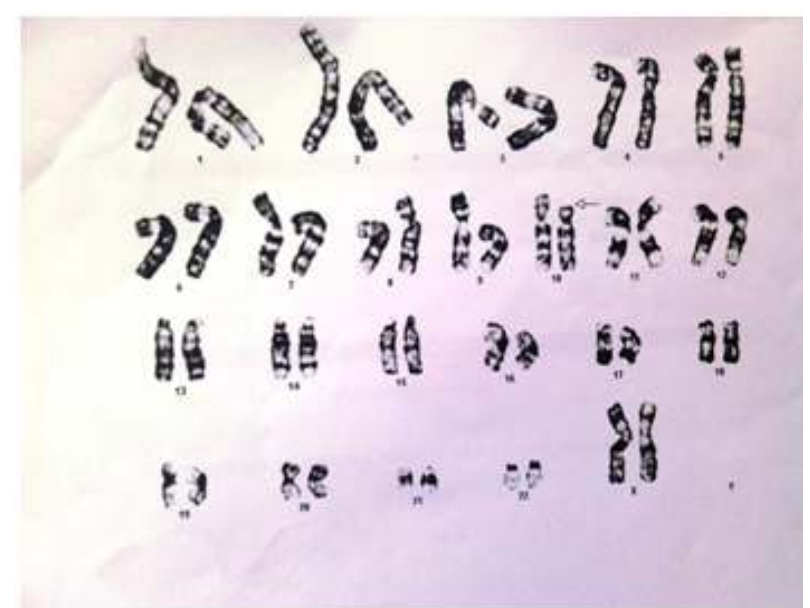

Figure 2: karyotype showing 46,XX, del(10)(p12.3 $\rightarrow$ 15)

\section{Discussion}

DGS is a common chromosomal disorder with an incidence of 1 in 4000 to $6000^{3}$. Some patients do not show all the features of classical DGS and therefore cause delay in diagnosis ${ }^{4}$. Palatal and speech problems together with congenital heart defect are the main issues in such patients who may be detected by speech pathologists or through ENT services ${ }^{5}$. Due to phenotypic overlap with other disorders the 22q11 deletion syndrome has expanded and velo-cardiofacial syndrome is the best known condition included in this syndrome ${ }^{6}$.

This child had the cardinal features of DGS (hypocalcaemia, hypoplastic thymus and congenital heart defects) as well as the characteristic facial features, cleft palate and feeding difficulties. The presence of thymic tissue (hypoplastic rather than an absent thymus) and circulating $\mathrm{T}$ cells lead to the diagnosis of partial DGS which is commoner than the complete DGS ${ }^{7}$. Despite the clinical, radiological, biochemical and immunological features being compatible with the diagnosis of partial DGS, chromosome analysis did not show chromosome 22q11 deletion. Instead the much rarer condition of chromosome 10p deletion was found.

$10 \mathrm{p}$ deletion is a very rare chromosomal abnormality ${ }^{8}$. Clinical entities reported are attributed to haploinsufficiency caused by deletion of genes located in close proximity to each other. Therefore $10 \mathrm{p}$ deletion is a contiguous gene deletion syndrome ${ }^{9}$ and clinical descriptions vary from deafness which occurs with deletion of the distal most region of the short arm of chromosome (10p15) to wider array of symptoms and signs when deletion of more proximal regions (10p12, p13,p14) occurs.
A specific region identified on the short arm of chromosome $10(10 p)$ is the DiGeorge critical region 2 (DGCR2) and deletion of $10 \mathrm{p} 13$ causes haploinsufficiency of DGCR2 ${ }^{10}$. In our patient karyotyping with high resolution banding showed deletion from 10p12 to $15^{10}$ and loss of DGCR2 explained the phenotype.

$10 \mathrm{p}$ deletion syndrome is also known to cause the HDR syndrome (hypoparathyroidism, deafness and renal abnormalities) when genes in p14, which is located very close to the DGCR2 region, is deleted ${ }^{11}$. We did not find any renal abnormality. However, sensori-neuronal hearing loss was found. In a review of 36 patients with $10 \mathrm{p}$ deletion and partial DGS, sensori-neuronal deafness was highly associated with $10 p$ deletion. Deafness is absent in DGS caused by $22 \mathrm{q} 11$ deletion and may help in differentiating which has been suggested in previous case reports ${ }^{11}$. This case supports this. In view of the genetic heterogeneity, we recommend karyotyping even when classical phenotype of DGS is present for accurate genotype-phenotype correlation.

\section{References}

1. Sullivan KE. DiGeorge syndrome/chromosome 22q11.2 deletion syndrome. Current Allergy and Asthma Reports 2001:1:438-44. http://dx.doi.org/10.1007/s11882-001-0029-Z

2. Kliegman EM, Stanton BF, St. Geme JW, Schor NF, Behrman RE. Nelson Textbook of Pediatrics. $19^{\text {th }}$ ed. Philadelphia: Elsevier Saunders; 2011.

3. Oskarsdóttir S, Vujic M, Fasth A. Incidence and prevalence of the 22q11 deletion syndrome: a population-based study in Western Sweden. Archives of Disease in Childhood 2004: 89; 14851.

http://dx.doi.org/10.1136/adc.2003.026880

4. Goldberg R, Motzkin B, Marion R, Scambler PJ, Shprintzen RJ. Velo-cardio-facial syndrome: A review of 120 patients. American Journal of Medical Genetics 1993:45:313-9. http://dx.doi.org/10.1002/ajmg.1320450307

5. Ryan AK, Goodship JA, Wilson DI, Philip N, Levy A, Seidel H, et al. Spectrum of clinical features associated with interstitial chromosome 22ql 1 deletions: an European collaborative study. Medical Genetics 1997; 34:798-804. http://dx.doi.org/10.1136/jmg.34.10.798 
6. Shprintzen RJ. Velo-cardio-facial syndrome. Progress in Pediatric Cardiology 2005; 20:18793.

http://dx.doi.org/10.1016/j.ppedcard.2005.04.009

7. Hsu HL, Hsiao PH, Hou JW, Tsai WY, Wang TR. Partial DiGeorge anomaly associated with 10p deletion. Journal of the Formosan Medical Association 1997; 96:996-9.

8. Hasegawa T, Hasegawa Y, Aso T, Koto S, Nagai $\mathrm{T}$, Tsuchiya $\mathrm{Y}$, et al. HDR syndrome (hypoparathyroidism, sensorineural deafness, renal aplasia) associated with del (10) (p13). American Journal of Medical Genetics 73: 4168.

http://dx.doi.org/10.1002/(SICI)10968628(19971

231)73:4<416::AID-AJMG9>3.0.CO;2-L
9. Daw SC, Taylor C, Kraman M, Call K, Mao J, Schuffenhauer S, et al. A common region of $10 p$ deleted in DiGeorge and velocardiofacial syndromes. Nature Genetics1996; 13:458-60. http://dx.doi.org/10.1038/ng0896-458

10. Melis D, Genesio R, Boemio P, Del Giudice E, Cappuccio G, Mormile A, et al. Clinical description of a patient carrying the smallest reported deletion involving $10 \mathrm{p} 14$ region. American Journal of Medical Genetics 2012; 158A:832-5.

http://dx.doi.org/10.1002/ajmg.a.34133

11. Lindstrand A, Malmgren H, Verri A, Benetti E, Eriksson M, Nordgren A, et al. Molecular and clinical characterization of patients with overlapping 10p deletions. American Journal of Medical Genetics 2010; 152A:1233-43. http://dx.doi.org/10.1002/ajmg.a.33366 